\title{
Students' Perception and Habits in Choosing Online Literature Sources for Seminar Papers
}

\author{
Irena Miljkovic Krecar, Maja Kolega, Vicko Krampus \\ University of Applied Sciences, VERN', Zagreb, Croatia
}

\begin{abstract}
As the authors' experience in lecturing shows students are ever more inclined to use the Internet as the main source of literature for seminar papers and other mandatory faculty tasks. Easy access to the Internet as well as the number and diversity of information has brought many advantages but has also made its consumers careless and uncritical. In this research 326 students were tested in order to determine their habits in finding, choosing and evaluating various literature sources for seminar papers. Participants were tested via an online questionnaire devised for this purpose. Moreover, 144 actual first year students' seminars have been analysed in order to determine their typical literature sources. Results show that majority of students (68\%) use the Internet as their first literature source. This tendency is even higher among final year students. Among nine listed sources, the highest credibility is given to scientific databases, and the lowest to blogs and forums. What is more, among five listed criteria for choosing an Internet text, the highest rate was given to website type. But in actual seminar papers, scientific databases were rarely used, as opposed to anonymous and non-reviewed online texts.
\end{abstract}

\section{Introduction}

In a modern digital society access to information is easier than ever before. That is surely a great advantage for students nowadays. However, in order to deal with such a plethora of information they need to develop particular skills required for identifying proper information sources, finding relevant information and using it effectively and ethically. To put it more simply, they need to be "information literate".

Information literacy can be defined as "the adoption of appropriate information behaviour to identify, through whatever channel or medium, information well fitted to information needs, leading to wise and ethical use of information in society" (Johnston and Webber [8] p.336). The term was used for the first time in 1974 by Paul Zurkowski (Chang et al. [4]), and according to the most frequently cited definition given by the American Library Association (see in Johnston and Webber, [8], p. 337) "to be information literate, a person must be able to recognize when information is needed and have the ability to locate, evaluate and use effectively the needed information." In other words, a person who is information literate has acquired a specific set of skills which include not only searching for and finding information, but also the evaluation and use of it for making decisions and solving problems.

The ability to discriminate between relevant and irrelevant information and reliable and unreliable sources of information is directly related to academic performance and success in the workplace. Therefore, it is important to understand how students choose relevant sources and participate in the whole process of search, selection, evaluation, and integration of information from different sources.

Researchers have shown that a majority of students predominantly use the Internet as the source for their class assignments (Barranoik [1], Jones [10], Julien and Barker [11], Chang et al. [4]). At the same time, students are quite uncritical of the information they find on web pages. To verify online information, information researchers suggest five criteria - accuracy, authority, objectivity, currency, and coverage - as a guideline for information credibility [13]. Accuracy includes the 
reliability of the information and whether the information can be verified offline. The authority marks who the author of the site is, what the author's qualifications, and affiliations are, and whether the Web site is recommended by a trusted source. Objectivity involves identifying the purpose of the site and whether the information provided is fact or opinion. Currency refers to whether the information is up to date, and Coverage means the comprehensiveness or depth of the information.

Many students could not estimate credibility and accuracy of web sites they used. Their evaluative criteria included both relevant and non-relevant (e.g. superficial aesthetic features) information selection, majority of them tend to assess the relevance of information on the basis of easy access and fail to cite sources appropriately (Barranoik [1], Fidel, et al. [5] Brem, Russell and Weems [3], Branch [2], Metzger, Flanagin, and Zwarun [14], Heinström [7], Julien and Barker [11], Halverson et al. [6]).

Furthermore, many students use the Internet to borrow texts and ideas without even mentioning the sources. That leads to another interesting phenomenon: increased access to the Internet has increased the so called "copy and paste culture" (Weber in Kohl [12]). Students find some information on the web, cut and paste it in a document without any citation, and sign it with their own names. According to Kohl [12], plagiarism is mostly a consequence of ignorance; intended plagiarism seems to be quite rare. The most frequent explanation for plagiarism is that students lack knowledge about how to avoid it (Soppe [15]).

Lecturers' experiences at the University of Applied Sciences VERN' in Zagreb, Croatia, confirm all the previous findings. Majority of students using the Internet in writing their seminar papers are not able to discriminate relevant from irrelevant sources. Wikipedia is frequently cited as a main source, information they use stem mostly from popular non signed articles and only few of them properly use scientific databases. That leads to the problem of not understanding the difference between scientific facts and pseudoscientific beliefs and many students lack the competence of interpretation and critical analysis of collected information.

\section{Goal and research questions}

The main goal of this research was to examine how students find, choose and evaluate literature for obligatory, individual seminar papers, with special emphasis on the online sources.

In order to answer the main goal, several research questions were set:
1. Where did or where would the students (for freshmen) find literature for their seminar papers?

2. How did students evaluate different online sources, according to their accuracy, precision, reliability, subjectivity and coverage?

3. How did students rank various criteria for choosing concrete Internet texts for their seminar papers?

4. How did students perceive their self-efficacy when writing seminar papers?

5. To what extent do students believe in online literature sources as opposed to hard copy texts?

6. Do students change their literature finding, choosing, and evaluating habits during their study?

7. What are the typical sources of seminar paper literature that students actually use?

\section{Procedure and participants}

The online questionnaire was sent to 1,300 first and final year students, to their individual student portals. 350 students replied. After excluding 24 questionnaires due to serious answer irregularities, 326 questionnaires remained, with all or partially missing data. Participants are all students of the University of Applied Sciences VERN' (Zagreb, Croatia) at six different undergraduate programs. The majority are Entrepreneurial Economics students (34\%) and Tourism and Hotel Management students (21\%). 151 participants are male and 171 female. Age ranges from 18 to 24 with dominant value of 22.6. 212 students are first year students and remaining are 114 final, third year students.

\section{Measures}

The questionnaire consisted of 12 closed type questions, among which 4 had text input possibilities (which were rarely used).

First five questions were general questions (age, gender, study, number of written seminar papers; $\mathbf{6}^{\text {th }}$ research question).

In the following two questions (that answer the $1^{\text {st }}$ research question) students were asked to determine what their main source of seminar paper literature so far had been (if they had written any) and in what order they had chosen listed sources of literature when they had been given a new seminar assignment. Listed sources were: the Internet, ask senior students for help, go to the library and ask the professor.

In question 8 ( $2^{\text {nd }}$ research question), students had to evaluate 9 different online sources according to their accuracy, precision, reliability, subjectivity, and coverage, on a five point scale. Online sources were: Wikipedia, news portals, specialized portals, 
blogs, forums, organizations and institutions websites, Google Scholar, social networks, scientific paper databases. By majority of listed source, examples of concrete examples of websites were given for the majority of possible sources.

In question $10\left(3^{\text {rd }}\right.$ research question) five different criteria for choosing a concrete online text for a seminar paper were listed. Participants had to rank those criteria according to their subjective importance. The criteria were: website type (e.g. is it a scientific database or an organization's website), text's author (e.g. their profession or title), text's position, according to the search engine, text's writing style (e.g. written in a professional language), and graphical design and overall impression of $a$ website.

Question $11\left(4^{\text {th }}\right.$ research question) consists of 7 items that form a scale called seminar paper literacy. Participants had to appraise how self-efficient they were (on a five point scale) in doing or knowing a specific seminar relevant topic (How to write a good seminar paper; How to cite literature properly; How to take other authors' ideas; How to discriminate relevant from irrelevant information; How to discriminate relevant from irrelevant literature sources; How to discriminate a fact from author's interpretation; What is plagiarism and what are its forms). Cronbach alpha of this scale is 0.79 .

Question $12\left(5^{\text {th }}\right.$ research question $)$ consists of 6 items that form a scale called Internet credence. Participants had to mark their agreement with listed items on a five-point scale (All the information needed, regardless of their type, could always be found on the Internet; Most of the information on the Internet has the same level of credibility as information found elsewhere; When I find some information on the Internet I usually don't check it elsewhere; Nowadays it is unnecessary to collect hard copy books when everything can be found online; When I find some key word text online, I usually don't look for its author; Most of the expert information I could need during my study can be found on the Internet). Cronbach alpha of this scale is 0.74 .

In addition to the applied questionnaire an analysis of actual students' seminar papers $(\mathrm{N}=144)$ has also been made $\left(7^{\text {th }}\right.$ research question). All the seminar papers were from the first year students, and were collected as a part of obligatory home assignment for psychology course. Seminar papers were on different, freely chosen topics, and although no concrete literature suggestions were given by professors, the condition was that seminar papers should use at least 3 different, relevant, scientific or expert sources.

\section{Results}

In total, most of the participants $(\mathrm{N}=116,36 \%)$ wrote less than 5 seminar papers through their entire education (Figure 1). Additional 113 (35\%) participants wrote more than 11 seminar papers, 72 (22\%) of them wrote 6 to 10 seminar papers, and 22 $(6.7 \%)$ had never written a seminar paper. Separate results for the $1^{\text {st }}$ year and the $3^{\text {rd }}$ year students show that among 212 first year students most $(\mathrm{N}=107$; $50.5 \%$ ) wrote less than 5 seminar papers and $19(9 \%)$ participants had never written a seminar paper. Among 112 final year students most $(\mathrm{N}=79,70.5 \%)$ wrote more than 11 seminar papers, and 3 of them (2.9\%) had never written a seminar paper.

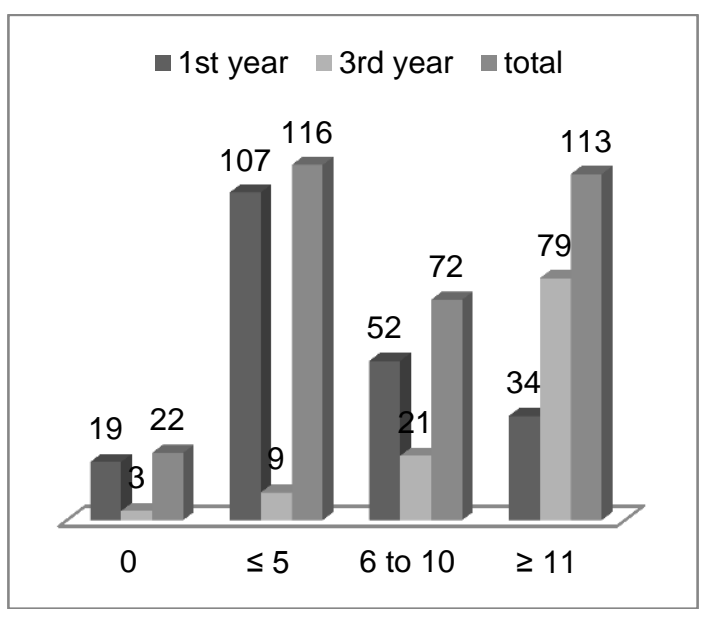

Figure 1. Number of written seminar papers for $1^{\text {st }}$ year students, $3^{\text {rd }}$ year students and total

While writing seminar papers in the past most of the participants found literature on the Internet (68\%), 14\% received sources from professors and additional $14 \%$ looked them up in the public or university library (Figure 2).

Remaining 3.4\% participants asked a friend and searched within their own private literature collection. The Internet is the main source of choice, regardless of the participant group, but students of the $1^{\text {st }}$ year are a bit more inclined to ask professors or obtain more literature information from professors than $3^{\text {rd }}$ year students, who, on the other hand, are more inclined to look for literature in a library, rather than to ask the professor. Moreover, the $1^{\text {st }}$ year students are more inclined to ask a friend for help than the $3^{\text {rd }}$ year students who are more inclined to search within their own libraries. 


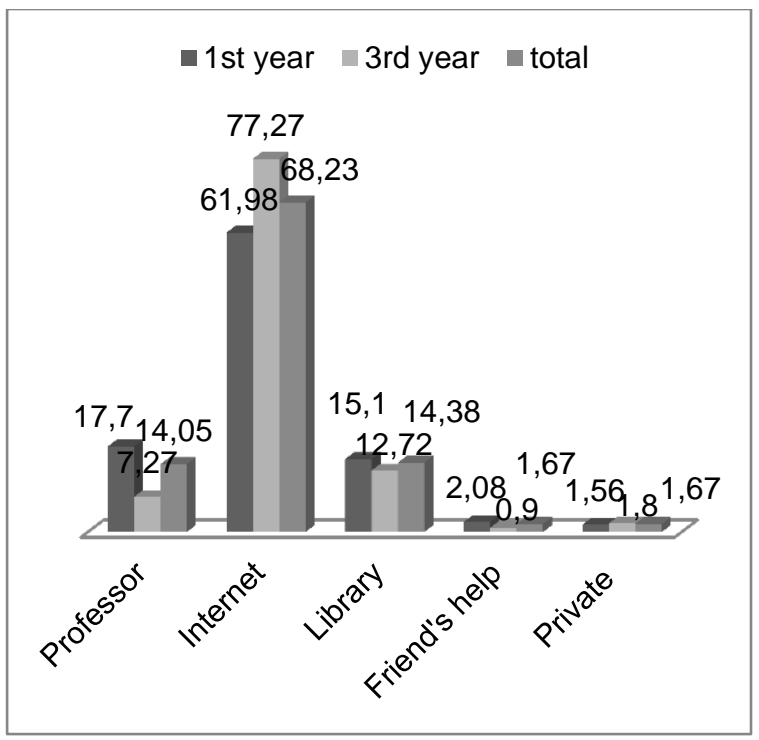

Figure 2. The main sources of literature in percentage

In table 1 descriptive statistics for student's estimation of accuracy, precision, reliability, subjectivity and coverage of nine different Online sources are given.

The accuracy means the exactness, e.g. correctness of the information. The precision refers to the accurate and detailed information, punctiliousness. Reliability is the extent to which we can rely on the source of the data and the data itself and, as mentioned in the introduction, whether the information can be verified offline. Reliable data is dependable, trustworthy, and reputable. The subjectivity involves whether the information provided is fact or opinion. Subjective information is based on personal opinions, interpretations, emotions or judgment. Objective information, on the other hand, is fact-based, measurable and observable. The coverage means the comprehensiveness or depth of the given information.

Students evaluated accuracy, precision, reliability, subjectivity and coverage of nine different sources, but the main problem was that the terms were not additionally explained. In other words, students could have different perception and connotative meaning of the same term, and the terms are very similar in meaning. Furthermore, it is possible that some of them didn't understand some terms and their evaluation could be influenced with their wrong understanding.
Table 1. Descriptive statistics for Accuracy, Precision and Reliability of nine Online Sources

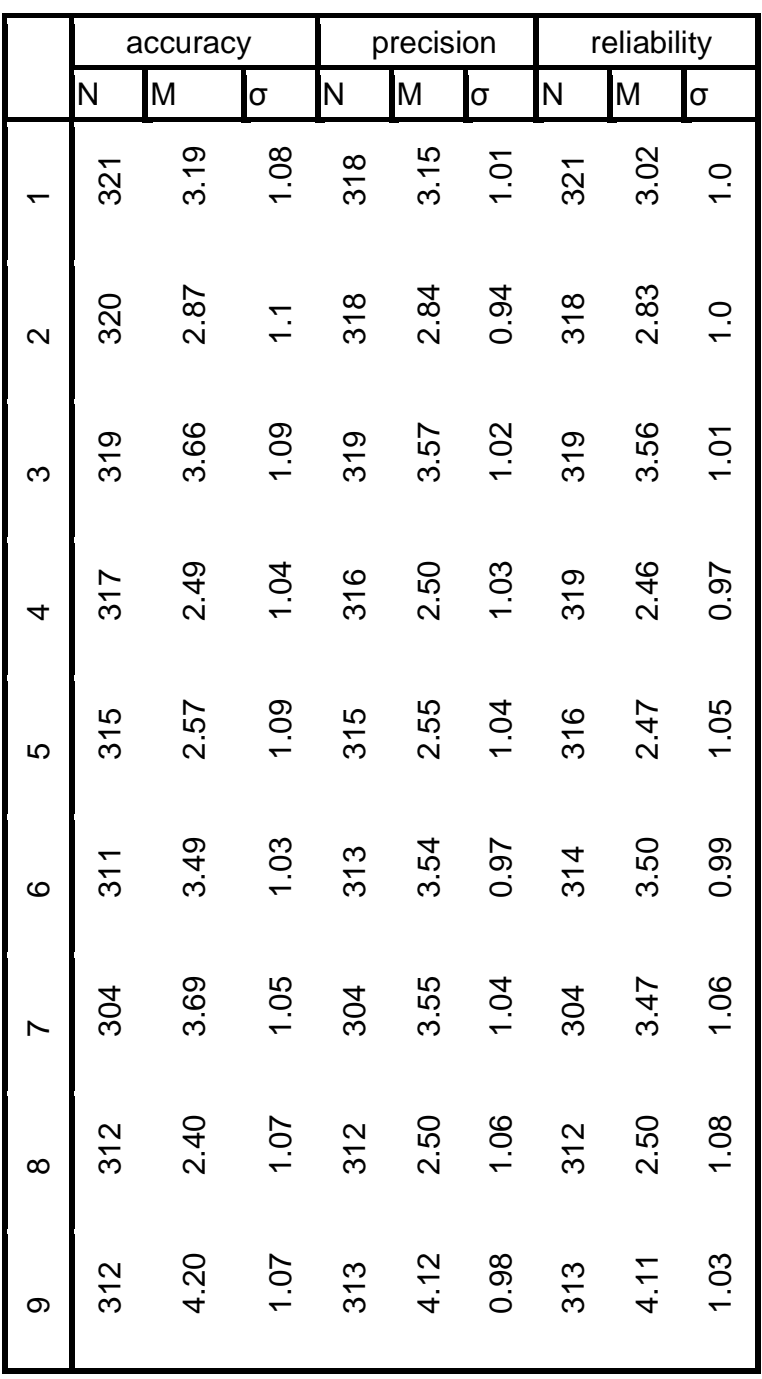

(1.Wikipedia, 2. News portals, 3. Specialized portals, 4 . Blogs, $5 . \quad$ Forums, 6. Organization/institution's websites, 7. Google. Scholar, 8. Social network, 9. Scientific databases).

Participants perceive the information from scientific databases as the most accurate, then information from Google.Scholar, specialized portals etc. The lowest accuracy was attributed to social network information, blogs and forums. It is similar with appraisals of precision, reliability and coverage where again scientific databases are perceived as more precise than blogs and social networks.

These results are in line with expectations and show that students understand different criteria in estimation of various on-line sources.

The results for information subjectivity are surprising. The highest objectivity was given to organizations' websites, and the least to Wikipedia. 
Table 1 also shows higher standard deviation scores for this variable, which calls clarity of this construct into question. It could also be the result of the lack of attention while filling in the questionnaire. Therefore, the evaluations of material subjectivity have been excluded from further analysis.

Table 2. Descriptive statistics for Subjectivity, and Coverage of nine Online Sources

\begin{tabular}{|c|c|c|c|c|c|c|}
\hline & \multicolumn{3}{|c|}{ subjectivity } & \multicolumn{3}{|c|}{ coverage } \\
\hline & $\mathrm{N}$ & M & $\mathbf{N}$ & M & $\mathbf{N}$ & M \\
\hline- & $\frac{\hat{n}}{m}$ & $\begin{array}{l}\stackrel{\infty}{\infty} \\
\stackrel{N}{N}\end{array}$ & $\stackrel{\hat{m}}{m}$ & $\begin{array}{l}\hat{\infty} \\
\stackrel{\alpha}{N}\end{array}$ & $\hat{\bar{m}}$ & \\
\hline$\sim$ & $\frac{\infty}{m}$ & $\frac{\infty}{\dot{m}}$ & $\frac{\infty}{m}$ & $\frac{\infty}{c}$ & $\frac{\infty}{m}$ & $\frac{\infty}{\stackrel{\infty}{\infty}}$ \\
\hline$m$ & $\frac{\sigma}{m}$ & $\stackrel{\sim}{\stackrel{\sim}{m}}$ & $\frac{\sigma}{m}$ & $\stackrel{N}{\stackrel{N}{m}}$ & $\frac{\sigma}{\infty}$ & $\stackrel{N}{\stackrel{N}{m}}$ \\
\hline$\theta$ & స్లి & 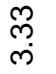 & స్లి & ભ্ల్ & 尺్లి & m్m \\
\hline ما & $\frac{\Lambda}{m}$ & 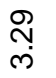 & $\frac{\hat{m}}{m}$ & & $\frac{\hat{m}}{m}$ & \\
\hline 6 & $\frac{\pi}{m}$ & $\begin{array}{l}\mathscr{g} \\
\stackrel{\leftrightarrow}{\infty}\end{array}$ & $\frac{\text { m }}{\text { m }}$ & $\begin{array}{l}\mathscr{O} \\
\dot{m}\end{array}$ & $\frac{\nabla}{m}$ & $\begin{array}{l}\dot{O} \\
\dot{m}\end{array}$ \\
\hline$\Lambda$ & \& & $\begin{array}{l}\Delta \\
\dot{m}\end{array}$ & \& & $\begin{array}{l}\Delta \\
\dot{0} \\
\dot{m}\end{array}$ & \& & $\begin{array}{l}\text { t' } \\
\dot{m}\end{array}$ \\
\hline$\infty$ & $\frac{\xi}{m}$ & 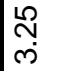 & $\frac{\tau}{m}$ & $\begin{array}{l}\stackrel{2}{N} \\
\stackrel{m}{m}\end{array}$ & $\frac{\Gamma}{m}$ & $\begin{array}{l}\stackrel{2}{\sim} \\
\stackrel{n}{m}\end{array}$ \\
\hline ه & $\frac{0}{m}$ & 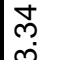 & $\frac{0}{m}$ & 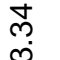 & $\frac{0}{m}$ & 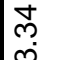 \\
\hline
\end{tabular}

(1.Wikipedia, 2. News portals, 3. Specialized portals, 4. Blogs, 5.Forums, 6. Organization/institution's websites, 7. Google. Scholar, 8. Social network, 9. Scientific databases).

On the 7 item scale called seminar paper literacy average result was $\mathrm{M}=3.26(\sigma=0.24)$. The highest result ( $\mathrm{M}=3.81)$ was for an item How to discriminate relevant from irrelevant information and the lowest $\mathrm{M}=3.44$ for the item How to take other authors' ideas.

On the 6 item scale called Internet credence average result was $\mathrm{M}=3.11(\sigma=0.74)$. The highest result $(\mathrm{M}=3.53)$ was for the item All the information needed (regardless of its type) can always be found on the Internet. The lowest result $(\mathrm{M}=2.73)$ was for the item Nowadays it is unnecessary to collect hard copy books, when everything can be found online.

Table 3. Differences between the first and the third (final) year students in evaluation of different criteria

\begin{tabular}{|c|c|c|c|c|c|}
\hline Variable & Stud. & $\mathrm{N}$ & $\mathrm{M}$ & $\sigma$ & $\mathrm{t}$ \\
\hline \multirow[t]{2}{*}{1} & $1^{\text {st }}$ & 209 & 3.19 & 0.8 & 0.73 \\
\hline & $3^{\text {rd }}$ & 108 & 3.25 & 0.64 & \\
\hline \multirow[t]{2}{*}{2.} & $1^{\text {st }}$ & 206 & 3.45 & 0.72 & -0.74 \\
\hline & $3^{\text {rd }}$ & 105 & 3.52 & 0.69 & \\
\hline \multirow[t]{2}{*}{3.} & $1^{\text {st }}$ & 206 & 2.58 & 0.79 & -1.71 \\
\hline & $3^{\text {rd }}$ & 107 & 2.74 & 0.75 & \\
\hline \multirow[t]{2}{*}{4.} & $1^{\mathrm{st}}$ & 207 & 2.56 & 0.77 & 0.05 \\
\hline & $3^{\text {rd }}$ & 109 & 2.56 & 0.73 & \\
\hline \multirow[t]{2}{*}{5.} & $1^{\text {st }}$ & 208 & 3.46 & 0.81 & $-3.04^{\star *}$ \\
\hline & $3^{\text {rd }}$ & 109 & 3.74 & 0.75 & \\
\hline \multirow[t]{2}{*}{6.} & $1^{\mathrm{st}}$ & 208 & 2.80 & 0.74 & $-2.82^{* *}$ \\
\hline & $3^{\text {rd }}$ & 109 & 3.05 & 0.75 & \\
\hline \multirow[t]{2}{*}{7.} & $1^{\mathrm{st}}$ & 200 & 3.62 & 0.86 & 1.66 \\
\hline & $3^{\text {rd }}$ & 103 & 3.4 & 0.77 & \\
\hline \multirow[t]{2}{*}{8.} & $1^{\text {st }}$ & 205 & 2.57 & 0.83 & -0.76 \\
\hline & $3^{\text {rd }}$ & 105 & 2.65 & 0.86 & \\
\hline \multirow[t]{2}{*}{9.} & $1^{\text {st }}$ & 204 & 4.10 & 0.83 & 0.22 \\
\hline & $3^{\text {rd }}$ & 106 & 4.08 & 0.80 & \\
\hline \multirow[t]{2}{*}{10.} & $1^{\mathrm{st}}$ & 206 & 3.52 & 0.64 & $-3.83^{* *}$ \\
\hline & $3^{\text {rd }}$ & 109 & 3.81 & 0.61 & \\
\hline \multirow[t]{2}{*}{11.} & $1^{\text {st }}$ & 209 & 3.07 & 0.74 & -1.29 \\
\hline & $3^{\text {rd }}$ & 112 & 3.18 & 0.73 & \\
\hline \multirow[t]{3}{*}{12.} & $1^{\text {st }}$ & 213 & 1.68 & 1.16 & $2.07^{*}$ \\
\hline & $3^{\text {rd }}$ & 110 & 1.42 & 0.91 & \\
\hline & All & 323 & 1.59 & 1.09 & \\
\hline \multirow[t]{3}{*}{13.} & $1^{\mathrm{st}}$ & 213 & 2.96 & 1.02 & -0.28 \\
\hline & $3^{\text {rd }}$ & 110 & 2.99 & 1.04 & \\
\hline & All & 323 & 2.97 & 1.03 & \\
\hline \multirow[t]{3}{*}{14.} & $1^{\mathrm{st}}$ & 213 & 2.93 & 1.13 & -0.29 \\
\hline & $3^{\text {rd }}$ & 110 & 2.97 & 1.07 & \\
\hline & All & 323 & 2.95 & 1.11 & \\
\hline \multirow[t]{3}{*}{15.} & $1^{\mathrm{st}}$ & 213 & 2.79 & 0.94 & -0.21 \\
\hline & $3^{\text {rd }}$ & 110 & 2.82 & 1.02 & \\
\hline & All & 323 & 2.80 & 0.96 & \\
\hline \multirow[t]{3}{*}{16.} & $1^{\mathrm{st}}$ & 173 & 1.76 & 1.14 & 1.11 \\
\hline & $3^{\text {rd }}$ & 91 & 1.6 & 0.87 & \\
\hline & All & 264 & 1.71 & 1.06 & \\
\hline \multirow[t]{3}{*}{17.} & $1^{\mathrm{st}}$ & 173 & 2.76 & 1.21 & -1.67 \\
\hline & $3^{\text {rd }}$ & 91 & 3.03 & 1.26 & \\
\hline & All & 264 & 2.86 & 1.83 & \\
\hline \multirow[t]{3}{*}{18.} & $1^{\mathrm{st}}$ & 173 & 3.16 & 1.20 & 1.00 \\
\hline & $3^{\text {rd }}$ & 91 & 3.00 & 1.38 & \\
\hline & All & 264 & 3.11 & 1.27 & \\
\hline \multirow[t]{3}{*}{19.} & $1^{\text {st }}$ & 173 & 2.98 & 1.06 & -0.17 \\
\hline & $3^{\text {rd }}$ & 91 & 3.00 & 1.01 & \\
\hline & All & 264 & 2.98 & 1.04 & \\
\hline \multirow[t]{3}{*}{20.} & $1^{\mathrm{st}}$ & 173 & 4.37 & 1.08 & 0.1 \\
\hline & $3^{\text {rd }}$ & 91 & 4.35 & 1.04 & \\
\hline & All & 264 & 4.36 & 1.06 & \\
\hline
\end{tabular}

(1.Wikipedia, 2. News portals, 3. Specialized portals, 4. Blogs, 5.Forums, 6. Organization/institution's websites, 7. Google. Scholar, 8. Social network, 9. Scientific databases, 10. Scale seminar literacy, 11. Scale Internet credibility, 
12. Look on the Internet Rank, 13. Ask help from other students Rank, 14. Go to the library Rank, 15. Ask the professor Rank, 16. Website type Rank, 17. Text's author Rank, 18. Text's position Rank, 19. Text's writing style Rank, 20. Graphical design and overall impression Rank).

In table 3 differences between the first and the final year students are shown. They have been tested with the t-test for independent samples. When assessing the total credibility of nine different online sources (average grade for accuracy, precision, reliability and coverage) significant differences are found for credibility of specialized portals $(\mathrm{t}=-3.04$, $\mathrm{p}<0.01)$ and news portals $(\mathrm{t}=-2.82, \mathrm{p}<0.01)$. In other words, senior students find themselves more credible in general. Furthermore, senior students assess themselves more seminar paper literate than the first year students $(\mathrm{t}=-3.83, \mathrm{p}<0.01)$.

When asked to rank different sources according to the probability of their use in future seminar papers, most of the participants choose the Internet again, as their choice number one. Other choices ( $g o$ to the library, ask the professor) got similar average ranks, ranging from 2.80 to 2.97 , with the highest rank (the least preferable choice) on asking fellow students for help for both groups. The only significant difference is found in ranking of the online sources, where third year students choose Internet more often as their number one choice $(\mathrm{t}=2.07, \mathrm{p}<0.05)$.

When asked to rank five different criteria for choosing a concrete online text for a seminar paper, all students chose website type as their first criterion and website graphical design as their last criterion. Other three criteria (text's author, text position, text's writing style) are of different importance for participants, but none of the differences were significant.

In conclusion, as the first and the final year students show little difference, and as they study 7 different study programs, with different seminar paper workloads, we tested if there are significant correlations in number of written seminar papers and different variables. Significant, positive correlation is found between number of written seminar papers and results on seminar paper literacy scale $(r=0.33$, $\mathrm{p}<0.01$ ). Also, the correlation between number of written seminar papers and evaluation of forums credibility is significant $(\mathrm{r}=0.12, \mathrm{p}<0.05)$. This means that the more seminar papers students write, the more credible they find forums as literature sources.

Finally, 144 actual first year students' seminar papers have been analysed. Seminar papers were an obligatory task at a psychology course. Students had to research a freely chosen psychology subject and received the instructions to use at least three different relevant, scientific or expert literature sources. These seminar papers were collected during the first half of the first semester. To the majority of students they were the first ones they had written during the study. Besides general instructions on how to write seminar papers, available online to all of the students, students also obtained a demo of a properly written psychology seminar paper for this task. Among 144 seminar papers, 12 students did not use or provide any literature source. Additional 3 students just wrote "online sources". In remaining 129 seminar papers, authors used 1 to maximum 6 sources, categorized and listed in picture 3. Majority of students used (mandatory) psychology textbook, then specialized portals (e.g. specialized health portals, Ministry of education portal etc.). Also, among the listed literature 63 anonymous texts were found, written by all kinds of quasi-experts. In only 3 cases online scientific journals were used.

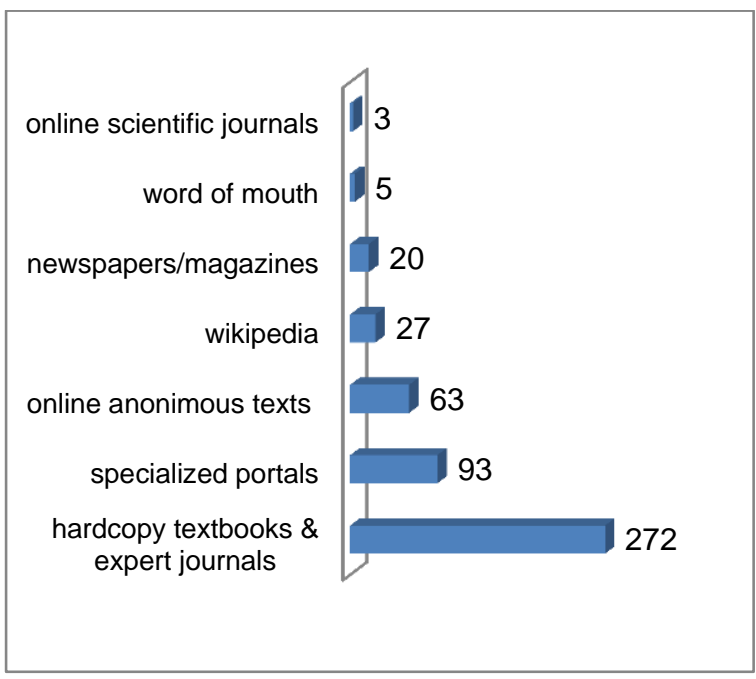

Figure 3. Frequency of used literature sources in 144 actual first year students' seminar papers

\section{Discussion}

Most of the students wrote seminar papers in the past (during their high school education) and their habits in choosing literature sources seem to have changed a little or not at all. As in the previous research, most of the participants $(68 \%)$ in this study chose online texts as their number one literature choice. This trend had not changed during their course of study, as the Internet is the first choice by first year students, as well as by final, third year students, who even use it in a higher percentage. Usage of other sources seems to change a little over time. Third year students show more independence 
in finding literature sources (more of them look for seminar paper literature in libraries), then freshmen who are more inclined to ask for help (either from a professor, or from other students).

Although the Internet is number one literature choice, average results on the Internet credence scale were not very high $(\mathrm{M}=3.11)$, which brings us to conclusion that students use the Internet mainly because of its easy access. Furthermore, although most of the students find online scientific databases to be the most credible online sources in general, in reality they do not use them very often. Also, when asked to rank various criteria for choosing an online text, majority of students choose website type, as their criterion number one. Figure 3 shows that in only 3 cases online scientific journals were used in actual seminar papers, although scientific databases (Emerald) are easily available to students on their personal student portals. We find several reasons to be the probable causes for this nonconformity between self-appraised online behaviour and actual online behaviour: 1) scientific database texts are often written in foreign languages (mainly English); 2) those texts are written in expert language, often difficult to understand; 3) searching within scientific database texts requires more effort than searching for texts by Google; 4) texts found by Google could look as credible as the ones in scientific databases (and students do not know how to discriminate them) and 5) many professors do not insist on the usage of scientific texts, and accept seminar papers of lower literature quality.

The last reason could also be attributed to the increment of self-appraised seminar paper literacy among third year students. That is, it is questionable whether this increment is due to actual improvement of seminar paper quality or to the acquired experience in how to find online literature faster, which is good enough for a passing grade. As seen in table 3, third year students find news portals and other specialized portals to have significantly higher total credibility, than first year students. A significant and positive correlation has been found between the number of written seminar papers and total credibility of blogs, which brings us to conclusion that over time students become experts in finding seminar paper literature everywhere on the Internet, and unfortunately professors accept it.

At the University of Applied Sciences, all students have access to written templates of seminar papers which includes obligatory structure, citing instructions, graphic design, and other important elements. What is more, students are required to attend seminar paper writing workshops during their first year of study. Nevertheless, experience shows that many of them make serious omissions in literature choices and citing, even in their final thesis. For example, often they cite Wikipedia or other non-reviewed and anonymous online texts as their literature sources.

To summarize, it is obvious that students need more structured guidance and support in developing their information literacy competence. Sanchez et al. [15] indicated four key areas in which students could need support: considering the source of the information, considering the evidence that was presented, thinking about how the evidence fit into an explanation of the phenomena, and evaluating the information with respect to prior knowledge. To address these needs, they developed an educational unit in which students were taught to consider the Source, Evidence, Explanation, and evaluate the information given in terms of their prior Knowledge (SEEK). Results have shown that learners who had received the SEEK training not only were better able to identify relevant from irrelevant sources, but also showed both higher overall levels of learning (Sanchez et al. [15],Wiley et al.,[17]).What is more, Holliday and Rogers [8], emphasize that students need support in understanding and avoiding plagiarism, which seems to be more effective than moral judgments. Heinstrom [7], and Barranoik [1], emphasize that motivation is the most significant variable in students searching behaviour. Many students just do not see any personal benefit in writing seminar papers and do not invest enough effort in that activity. Their topics are more often assigned than chosen, and their use of information is simply seen as a way to finish the task rather than as a way to develop their own competence.

Still, it is not enough only to focus on students and their development. Lecturers should be competent as well and at the same time it is important for them be motivated to give clear and direct feedback to every student paper. Due to heavy workload and time pressure in correcting student papers, it can be assumed that some lecturers just do not pay full attention to every student's paper and accept papers below quality standards.

Chang et al. [4] suggest better collaboration between lecturers and school librarians, because in their experience students tend not to use the libraries, even their own school library. Only $14 \%$ of students from this sample use libraries. The responsibility of the lecturers should be to motivate their students to visit libraries more often and to inform themselves about their possibilities.

Johnston and Webber [9], proposed the model which requires that all members of the university administrators, academics and researchers, as well as students, develop better information literacy skills. In other words, when academic staff pays more 
attention to information literacy and develop their competence it can influence their pedagogic thinking and the way they conceive of their own discipline.

\section{Research Limitation}

Certain limitations of this research are given as well as the directions for future research. First of all, the sample is limited to the students of University of Applied Sciences VERN' Zagreb, Croatia. This university is a private university with a strong entrepreneurial direction. Many students who choose to study here are more oriented towards acquiring practical then academic skills and it can be assumed that they do not have enough motivation for academic writing. The form of this survey was easy to fill. Despite this, some students either had difficulties with the online form, or they lacked the motivation to read different instruction for each set of the items. What is more, some terms in the survey were not additionally described (accuracy, precision, reliability, subjectivity, and coverage) and it is likely that some students just did not understand the meaning of them (it refers especially to the term subjectivity, as it was discussed before).

\section{Conclusion}

To conclude, the answers to the previously set research questions are given below.

Majority of the 326 tested participants found or would look for information for their seminar papers on the Internet $(68 \%)$. Other ranked sources were: going to a library (14.38\%), asking the professor $(14.05 \%)$, asking a senior student for help (1.67\%), or using a private library $(1.67 \%)$.

The highest appraisals for accuracy precision, reliability and coverage of different sources were given to scientific databases, and the lowest to blogs, forums and social networks. For subjectivity, the highest appraisal is given to organization/institutions' websites, and the lowest to the Wikipedia.

When asked to rank five different criteria for choosing a concrete online text for a seminar paper, all the participants chose website type as their first criterion and website graphical design as their last criterion. Self-efficacy in writing seminar papers was estimated on the 7 item scale called seminar paper literacy. Average result was $\mathrm{M}=3.26(\sigma=0.24)$. The 6 item scale called Internet credence measured how much students believe in online sources as opposed to hard copy text. Average result on this scale was $\mathrm{M}=3.11(\sigma=0.74)$.

The first and the final year students show little difference in their habits in using information.
Nevertheless significant, positive correlation is found between number of written seminar papers and results on seminar paper literacy scale. Furthermore, positive correlation between number of written seminar papers and evaluation of forums credibility is significant too.

Typical sources of seminar paper literature that students actually use were measured through analysis of 144 seminar papers made for a psychology class. Majority of students used (mandatory) psychology textbook for their papers, then specialized portals (e.g. specialized health portals, Ministry of education portal etc.). Scientific journals were used in only 3 cases.

\section{Future Research}

In this research actual seminar papers from third year students have not been analysed, as no comparable course exists on the third year. It would be useful for some future researches to test whether increased seminar paper literacy is related to increased paper quality.

Moreover it would be interesting to determine how lecturers motivate their students not only to use information, but also to analyse and interpret it, to construct new meaning and to create new perspectives from it. Furthermore, which motivational strategies are the most effective with different types of students.

Finally it would be useful to test how high is lecturers' motivation in correcting seminar papers, but also their self-efficacy in managing online information and in evaluating student's seminars.

\section{References}

[1] L. Barranoik, "Research success with senior high school students" School Libraries Worldwide, 2001, 7(1), pp.28-45.

[2] J. Branch, "Instructional intervention is the key: Supporting adolescent information seeking." School Libraries Worldwide, 2003, 9(2), pp. 47-61.

[3] S.K. Brem, J. Russell, L. Weems, "Science on the web: Student Evaluations of scientific arguments." Discourse Processes, 2001, 32 (2-3), pp. 191-213.

[4] Y. Chang, X. Zhang, I.A. Mokhtar, S. Foo, S. Majid, B. Luyt, Y. Theng, “Assessing students' information literacy skills in two secondary schools in Singapore." Journal of information literacy, 2012, 6(2), pp. 19-34. 
[5] R. Fidel, R. K. Davies, M. H. Douglass, J. K. Holder, et al. "A Visit to the Information Mall: Web Searching Behaviour of High School Students" Journal of the American Society for Information Science, 1999, 50, 1, pp. 24-37.

[6] K.L. Halverson, M.A. Siegel, S.K. Freyermouth, Non-science majors ${ }^{\text {ee }}$ critical evaluation of websites in a biotechnology course. Journal of Science Education and Technology, 2010, 19, pp. 612-620.

[7] J. Heinström, "Fast surfing for availability or deep diving into quality - motivation and information seeking among middle and high school students. Information Research, 2006, 11 (4).

[8] W. Holliday, J. Rogers, "Talking about information literacy: the mediating role of discourse in a college writing classroom. portal: Libraries and the Academy, 2013, 13:3. pp. 257-271.

[9] B. Johnston, S. Webber, "Information literacy in higher education: a review and case study." Studies in Higher Education, 2003, 28(3),pp. 335-352.

[10] Jones, S. The Internet Goes to College. How Students are Living in the Future with Today's Technology. Pew Internet and American Life Project, Washington, DC, 2002.

[11] H. Julien, S. Barker, "How high-school students find and evaluate scientific information: A basis for information literacy skills development." Library and Information Science Research, 2009, 31(1), pp. 1217.

[12] K.E. Kohl, "Fostering academic competence or putting students under general suspicion? Voluntary plagiarism check of academic papers by means of web-based plagiarism detection system." Association for Learning Technology - Conference Proceedings, 2011, 079, pp. 90-99.

[13] M.J. Metzger, "Making sense of credibility on the Web: Models for evaluating online information and recommendations for future research". Journal of the American Society for Information Science and Technology, 2007, 58(13), pp. 2078-2078.

[14] M.J. Metzger, A.J. Flanagin, L. Zwarun, "College student Web use, perceptions of information credibility, and verification behaviour". Computers and Education, 2003, (41), pp. 271-290.
[15] C.A. Sanchez, J. Wiley, S.R. Goldman, "Teaching students to evaluate source reliability during internet research task,

http://www.ccs.neu.edu/course/is4800sp12/

resources /sanchez.pdf (15.11.2014.)

[16] K.F.B. Soppe, "Student plagiarism: Intended or accidental?" Social Cosmos 2013, 4, 1, pp. 51-56.

[17] J. Wiley, S.R. Goldman, A.C. Graesser, C.A. Sanchez, I.K. Ash, J.A. Hemmerich, "Source evaluation, comprehension, and learning in Internet science inquiry tasks". American Educational Research Journal, 2009, 46(4), pp. 1060-1106. 